them had sliding hiatal herniae. Of the 12 patients with abnormalities demonstrated by manometric studies, four had sliding hiatal herniae (two with adequate barrier pressures at the inferior sphincter) and eight evidence of incoordination of primary peristalsis (Fig. 4). Cineradiography showed abnormalities in 11 patients, of whom six had sliding hiatal herniae and five abnormal peristalsis. The pharyngeal pressures in all four groups were within normal limits.

\section{Discussion}

In considering the abnormalities found in the gastrointestinal system (excluding the oesophagus) in association with diabetes, Katz and Spiro (1966) maintained that the changes could not readily explain the symptoms and often were not associated with any clinical manifestations. Similar views were previously expressed by Rundles (1945), who, in discussing the oesophageal changes, considered that the whole problem was a challenge.

Mandelstam and Leiber (1967) concluded that the oesophageal motor dysfunction was a common finding in diabetic neuropathy-gastroenteropathy, and that on occasion it results in dysphagia. In their group 12 had oesophageal dysfunction but only three had symptoms, while their control group had no changes at all.

The present study indicated that abnormal oesophageal function was not limited to one group and therefore that the abnormality is not specific or exclusive to the diabetic neuropathy group. The chief finding was an incoordination of the primary peristalsis in the body of the oesophagus. In each group there were cases of sliding hiatal herniae associated with both normal and abnormal sphincteric action and peristalsis. With the exception of the non-diabetic symptomatic group, however, there was no correlation between the clinical picture and the cineradiographic motility studies. Similar findings of oesophageal dysfunction were reported in alcoholic neuropathy and normals (Winship et al., 1968).

Furthermore, there is no explanation of the pathogenesis which could account for these changes occurring in all the groups at all ages. Vagal degeneration and myopathy of the oesophageal muscle have been incriminated, but with no absolute proof. Recently it has been considered that diabetic neuropathy is a metabolic defect predominantly affecting fat metabolism within the cell which is associated with hyperplasia of the basement membrane (Bischoff, 1968). This latter investigation was carried out on peripheral nerves, and not on the oesophagus or on the rest of the gastrointestinal tract.

The conclusion therefore drawn from the present study is that identical cineradiographic and manometric evidence of oesophageal dysfunction can occur in all four groups investigated and not only in those affected by diabetes, with or without neuropathy.

\section{REFERENCES}

Bischoff, A. (1968). German Medical Monthly, 13, 214 Katz, L. A., and Spiro, H. M. (1966). New England fournal of Medicine, 275, 1350

British Medical fournal, 1967, 4, 311.

Mandelstam, P., and Leiber, A. (1967). Fournal of the American Medical Association, 201, 582.

Rundles, W. R. (1945). Medicine, 24, 111.

Winship, D. H., Caflisch, C. R., Zboralske, F. F., and Hogan, W. J. (1968). Gastroenterology, 55, 173.

\title{
Selective Vagotomy without Drainage. An Interim Report
}

\author{
H. BURGE,* M.B., F.R.C.S.; C. MACLEAN, $\dagger$ M.D., D.M.R.D., M.R.C.P.ED. \\ R. STEDEFORD, $\ddagger$ PH.D., B.M., F.R.C.S. ; G. PINN,§ M.B., M.R.C.S.; D. HOLLANDERS,§ M.SC. M.B., B.S.
}

[Wrth Special Plate between Pages 692-693]

Summary : The results of surgical treatment for duodenal ulcer were compared in two groups of patients -51 who had undergone selective vagotomy without drainage and 17 who had had selective vagotomy and pyloroplasty. It is suggested that in the absence of organic pyloric or duodenal stenosis the former method seems both preferable and desirable, since postoperatively dumping does not occur and there is a steady improvement in gastric emptying.

\section{Introduction}

The addition of a drainage procedure (pyloroplasty or gastrojejunostomy) to a truncal abdominal vagotomy is now standard practice. This was introduced soon after vagotomy was first used in the treatment of duodenal ulcer, in order to relieve the pronounced gastric retention which, it was found, followed truncal vagotomy alone. At that time vagotomy was often performed in patients with advanced duodenal disease with stenosis. We are not aware of published results describing the effects of truncal vagotomy in the absence of stenosis in man.

* Surgeon, West London Hospital, London W.6.

† Radiologist, West London Hospital, London W.6.

$\mp$ Resident Assistant Surgeon, West London Hospital, London W.6.

House-Surgeon, West London Hospital, London W.6.
Total abdominal (truncal) vagotomy (Fig. I) denervates the pylorus, prepyloric stomach, and duodenal bulb, but bilateral selective vagotomy (Fig. II), by virtue of its anterior selective nerve section, preserves the vagal supply of these parts. Our work was started in the hope that this preservation might allow normal gastric emptying without a drainage operation. Dumping, which is more common and more severe than we had earlier thought after vagotomy and drainage, might then be eliminated. Probably dumping is caused not by vagotomy but by excision of the pylorus or by bypassing it as in gastric resection or gastrojejunostomy, or by division of it as in pyloroplasty.

There are other possible advantages of omitting the pyloroplasty. It may be that some postoperative diarrhoea is also due to loss of the normal pylorus, and it seems that steatorrhoea may be caused by the pyloroplasty rather than by the vagotomy (Wastell, 1966). Again, the risk of leakage from the pyloroplasty is eliminated. Soiling of the peritoneal cavity and the wound should not occur.

With these considerations in mind it was decided to perform bilateral selective vagotomy without drainage in a series of patients with duodenal ulcer, some with no duodenal narrowing whatever and some with moderate though not advanced organic stenosis. A preliminarv report of this work has already been made (Burge, 1968). The success or failure of this 
method must depend on the incidence and degree of persistent gastric retention when pyloroplasty is omitted compared with the standard operation of selective vagotomy and a properly made pyloroplasty.
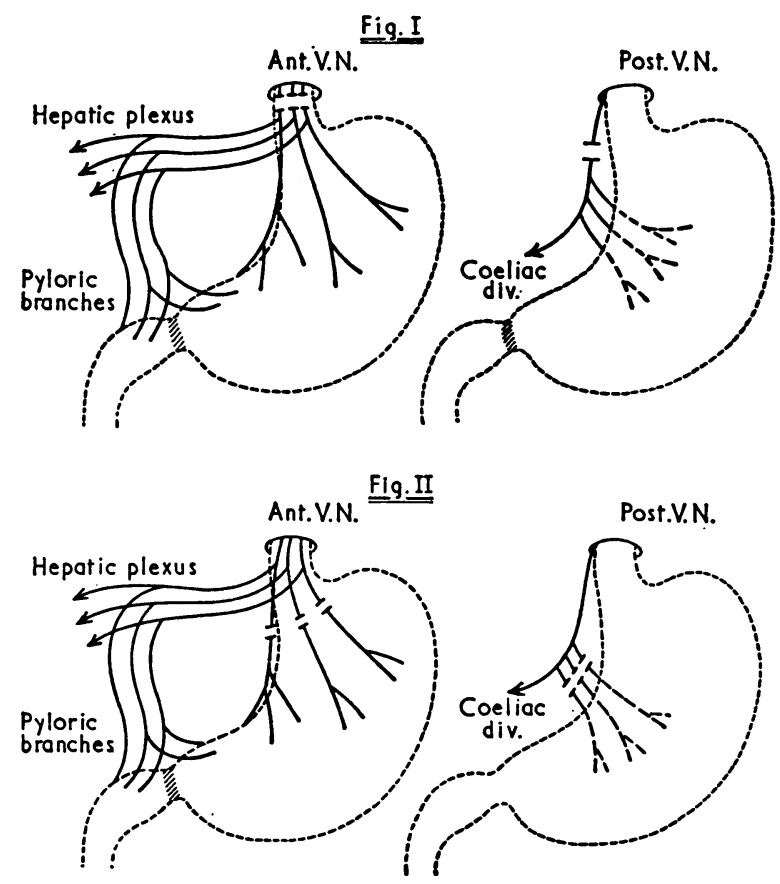

Fig. I.-Total abdominal vagotomy. FIG. II.-Bilateral selective vagotomy.

\section{Method}

The 31 patients (series 1) who were admitted to hospital between February and October 1967 for surgical treatment of duodenal ulcer comprised 22 men and 9 women. All had radiological evidence of duodenal ulceration, and in some the two-hour film of the standard barium meal series showed evidence of gastric retention. At operation the calibre of the pyloroduodenal channel was estimated by inspection and by passing the cuffed gastric tube (about $\frac{1}{2}$ in. $(1.25 \mathrm{~cm}$.) diameter), introduced through the mouth, used in the electrical stimulation test for completeness of vagotomy. When the gastric tube could be passed into the duodenum and the cuff was fully inflated there was thought to be no significant stenosis, so the pyloroplasty was omitted. In some patients with obvious organic narrowing the tube, but not the cuff, passed, and in these, too, the pyloroplasty was omitted. A bilateral selective vagotomy was then performed, completeness of gastric nerve section being confirmed by the electrical stimulation test.

Having observed these patients (series 1) for more than a year we were led to use the method again. The next 20 patients (series 2) have been studied and are reported here.

Postoperative assessment in the outpatient department comprised: (1) an inquiry into symptoms of gastric retention-for example, foul eructations or vomiting ; and (2) a "special" barium meal-that is, $50 \mathrm{ml}$. of barium emulsion, taken onethind immediately before, one-thind during, and one-third immediately after a standard breakfast of bacon, egg, and bread, together with two cups of tea ; this meal was followed by an $x$-ray examination of the abdomen made nine hours later with the patient standing, no food or drink having been taken during the interval.

The 51 patients (series 1 and 2) fall into two groups; in the first are the 36 cases (16 in series 1 and all 20 in series 2 ) in whom there was little or no visible narrowing of the duodenum at operation and no radiological evidence of gastric retention in the routine preoperative two-hour barium films. In the other group are 15 patients in series 1 in whom some degree of organic stenosis was found. In these the preoperative $x$-ray films usually showed significant residual barium in the stomach after two hours.

The "special" meal examination was carried out in two other groups of patients for comparison: (1) In 17 patients randomly selected who had undergone bilateral selective vagotomy and pyloroplasty at this hospital in 1966 or 1967 . The pyloroplasty incision was made to divide the whole of any narrowed segment and a single layer of interrupted thread sutures was used according to the Heineke-Mikulicz method. (2) In 15 volunteer patients admitted to hospital with other conditions and with no history of peptic ulcer or dyspepsia.

\section{Results}

The degree of gastric retention was estimated by using the "special" barium meal. The amount of barium remaining in the stomach was arbitrarily expressed as $0,+,++,+++$ (Special Plate, Figs. 1 to 4 ). The results of these $x$-ray examinations in relation to the time elapsed since operation are shown in Tables I to $\mathrm{V}$ for five groups of patients.

TABLE I.-Fifteen Patients Without Known Gastric or Duodenal Disease Undergoing Routine Minor Surgery ("Normals")

\begin{tabular}{|c|c|c|c|c|c|}
\hline 1 & 0 & 6 & 0 & 11 & 0 \\
\hline 2 & 0 & 7 & 0 & 12 & 0 \\
\hline 3 & 0 & 8 & 0 & 13 & 0 \\
\hline 4 & 0 & 9 & 0 & 14 & + \\
\hline 5 & 0 & 2 & 0 & 15 & + \\
\hline
\end{tabular}

TABle II.-Seventeen Patients After Selective Vagotomy and Pyloroplasty

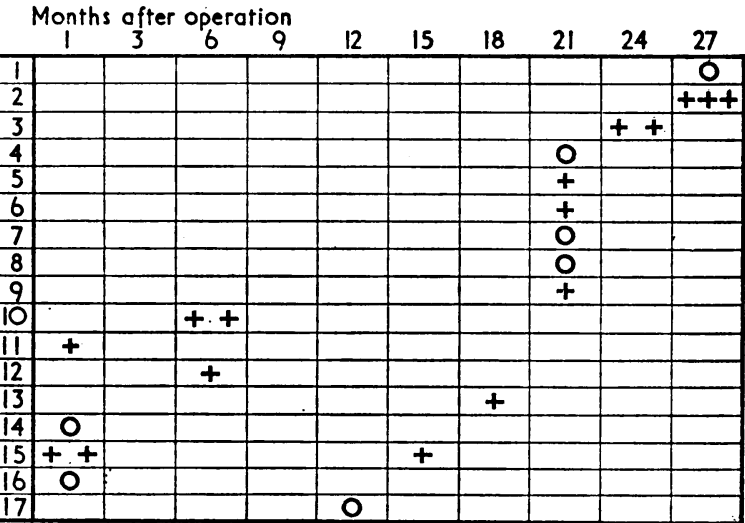

TABLE III.-Fifteen Patients After Selective Vagotomy Without any Drainage Operation, With Some But Not Severe Organic Pyloroduodenal Stenosis (Series 1) Months after operation

\begin{tabular}{|c|c|c|c|c|c|c|c|c|c|c|}
\hline \multicolumn{5}{|c|}{1136} & \multirow{2}{*}{$\frac{12}{++1}$} & \multirow[t]{2}{*}{15} & 18 & \multirow[t]{2}{*}{21} & \multirow[t]{2}{*}{24} & \multirow[t]{2}{*}{27} \\
\hline$T$ & & $1+++$ & & & & & $t+$ & & & \\
\hline 2 & & + & & 0 & & & & & & \\
\hline 3 & & $t+$ & & & & & & & & \\
\hline 4 & . & & & & & & $+t$ & & & \\
\hline 5 & & $+t$ & & & & $+t$ & & & & \\
\hline 6 & ++ & & +++ & $+t$ & & 0 & & & & \\
\hline 7 & & $+t$ & & & & $+t$ & & & & \\
\hline 8 & + & & & & ++ & & & & & \\
\hline 9 & $++t$ & & & & $+t$ & & & & & \\
\hline 10 & & & & & $+t$ & & & & & \\
\hline 11 & $++t$ & & & & $t+$ & & & & & \\
\hline 12 & & & & & + & & & & & \\
\hline 13 & & Lost t & o follor & w-up & & & & & & \\
\hline 14 & & & ++ & & & & & & +8 & deded \\
\hline 15 & + & & & & & & & & & \\
\hline
\end{tabular}

We have tried to evaluate this method of assessing gastric retention by repeating the "special" meal on the same patient. Although gastric retention may diminish as time passes, this method gives consistent results at any given period, and seems satisfactory for our purpose. The degree of retention after operation is no greater in those patients with selective vagotomy 
without drainage and without organic stenosis than in those with selective vagotomy and pyloroplasty.

TABLE IV.-Sixteen Patients After Selective Vagotomy Without Drainage Operation and Without Pyloroduodenal Stenosis (series 1)

Months after operation
\begin{tabular}{|c|c|c|c|c|c|c|c|c|c|c|}
\hline 1 & 1 & 3 & 6 & 9 & 12 & 15 & 18 & 21 & 24 \\
\hline 2 & & ++ & & & & & ++ & + & \\
\hline 3 & & ++ & & 0 & & & & & \\
\hline 4 & & & ++ & & & & ++ & & ++ \\
\hline 5 & & & & & +++ & re-op. pyl. odded & \\
\hline 6 & & ++ & & & & 0 & & & \\
\hline 7 & & & & & & & + & & + \\
\hline 8 & & & & & & & 0 & & \\
\hline 9 & & 0 & & & & & & & \\
\hline 10 & & & & & +++ & & ++ & & \\
\hline 11 & +++ & & +++ & ro-op. pyl.odded & ++ & & & \\
\hline 12 & & + & & & + & & + & & \\
\hline 13 & & & & & ++ & & & & \\
\hline 14 & & ++ & & & & & 0 & & \\
\hline 15 & & & 0 & & & & & & \\
\hline 16 & & ++ & & & +++ & & & & ++ \\
\hline
\end{tabular}

As we studied our subject more thoroughly we came to think that in series 1 we had not always taken enough care to exclude minimal organic duodenal stenosis. A small degree of narrowing of the muscle coat may hide a more severe, mucosal narrowing. This is well demonstrated in the stomach in Fig. 5 (Special Plate). There is minimal narrowing of the muscle coat of the greater curve opposite a low lesser-curve gastric ulcer. The lumen of the stomach is very much narrowed by a severe mucosal stenosis. It is of some interest to note the perforated ulcer in the duodenum. Probably, too, the degree of mucosal stenosis in the duodenum is of ten more severe than can be suspected from the external appearance at operation.

In series 2 more effort was made to exclude even early stenosis by preoperative "special" barium studies and by more careful selection of cases based on the operative finding.

Although only six months have passed since the operation was performed on the first of this series, we are now able to report the results of the postoperative "special" meals in the first 20 cases. These radiological results are better than those at the same postoperative time in series 1 (Table V).

TAble V.-Twenty Patients After Selective Vagotomy Without Pyloroduodenal Stenosis (series 2)

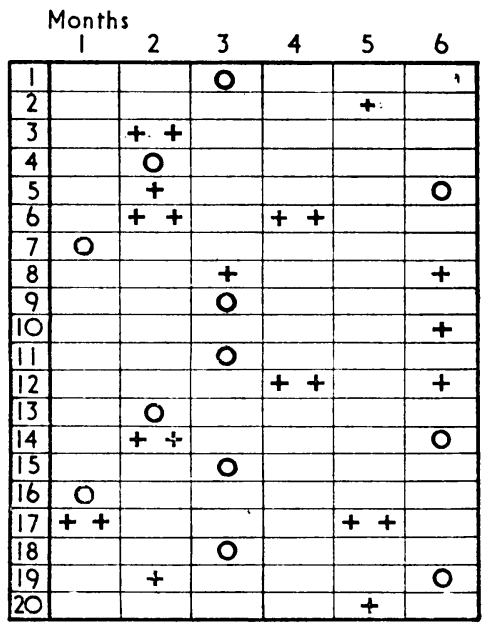

Discussion

We came to use selective vagotomy without drainage because this operation preserves the innervation of the distal stomach and pylorus, and in the hope that it would prevent the complications due, perhaps, to the pyloroplasty itself-dumping, bilious regurgitation, and perhaps persistent diarrhoea. A recent study of patients after selective vagotomy and pyloroplasty, performed for lesser curve gastric ulcers showed that 7 out of 70 had persistent dumping, and in a wider inquiry dumping after selective vagotomy and pyloroplasty appeared to be a more frequent and serious problem than we had earlier realized.

The function of the vagal supply to the pylorus and the prepyloric stomach is still uncertain. Franksson (1948) concluded that the prepyloric branches from the anterior vagus were motor, but other workers (Stavney et al., 1963) have been uncertain about this. Probably a large proportion of the nerve fibres here are sensory, since $85 \%$ of the fibres in the main abdominal vagal trunks are afferent (Agostoni et al., 1957) and are in some way concerned in the co-ordination of gastric emptying.

As early as 1901 Van Yzeren produced chronic gastric ulcers in the rabbit by truncal vagotomy and found that these were cured by subsequent gastrojejunostomy. Linares et al. (1964) repeated this work and found that either gastrojejunostomy or pyloroplasty protected the animal from gastric ulceration.

Perhaps the only sequelae which might be expected to follow selective vagotomy without drainage are the foul eructations caused by gastric retention and, of course, lesser curve gastric ulcer, also secondary to gastric stasis. In no case in our series, however, has gastric ulceration occurred. Perhaps this is because all these patients have had a complete proximal gastric vagotomy, established by means of the electrical stimulation test. Not only has the cephalic phase of gastric acid secretion been abolished but the hormonal phase has, too, been diminished. Also it seems that genetic factors are important in the production of gastric ulceration, for many patients with gastric retention seem never to develop gastric ulcers. It might be argued by some that gastric retention in these patients may later cause lesser curve gastric ulcers and that the follow-up is too short. Nevertheless, our own studies-in this series-of gastric retention after vagotomy with a properly made singlelayer pyloroplasty show that gastric retention is more profound and persistent than in well-chosen cases without pyloroplasty. This opinion is certainly supported by Buckler's (1967) work.

The incidence and degree of gastric retention in series 1 , 18 to 24 months after selective vagotomy without drainage, is no more than after selective vagotomy with a single-layer pyloroplasty. Thus the criticism that selective vagotomy without drainage might lead to gastric ulcer should no more apply than to the now standard operation of selective vagotomy with pyloroplasty.

Our estimate of gastric emptying is not a strictly quantitative one, but it does use a natural process-namely, a standard semi-solid meal. Nine hours is longer than a normal stomach should take to empty under these conditions, but it is interesting that patients with selective vagotomy and pyloroplasty should also have prolonged emptying times without having appropriate symptoms. This accords with the findings of Buckler (1967) but not with those of George (1968), the latter using a volume of fluid to fill the stomach. The apparent discrepancy here may be due to the use of liquid rather than solid gastric content to measure the emptying rate. Another important factor is the method of making the pyloroplasty; for example, whether a one- or two-layer closure is used.

Another feature of these patients without drainage is the steady improvement in gastric emptying over the course of months. This may not be so for retention following selective vagotomy and pyloroplasty. The flatulence and foul eructations which may occur very soon after operation, and associated with a large nine-hour residue in the "special" barium meal, disappears with time (Special Plate Figs. 6 and 7). One patient put on the waiting-list for addition of a pyloroplasty because of eructation of foul wind reported, before being admitted, to say that he was now in every way well.

We believe that selective vagotomy without drainage not only avoids the very small risk of a pyloroplasty leak but 
H. BURGE $E T A L$.: SELECTIVE VAGOTOMY WITHOUT DRAINAGE

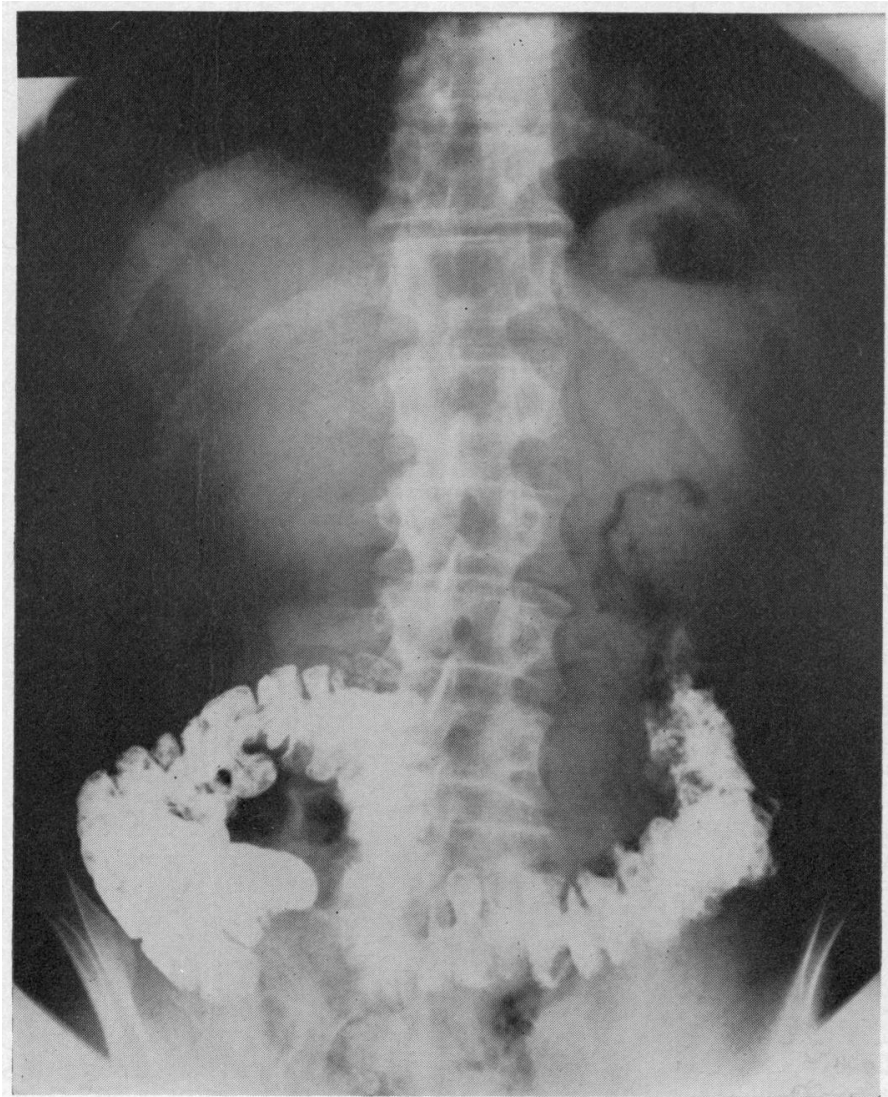

FIG. 1.-Gastric retention 0 .

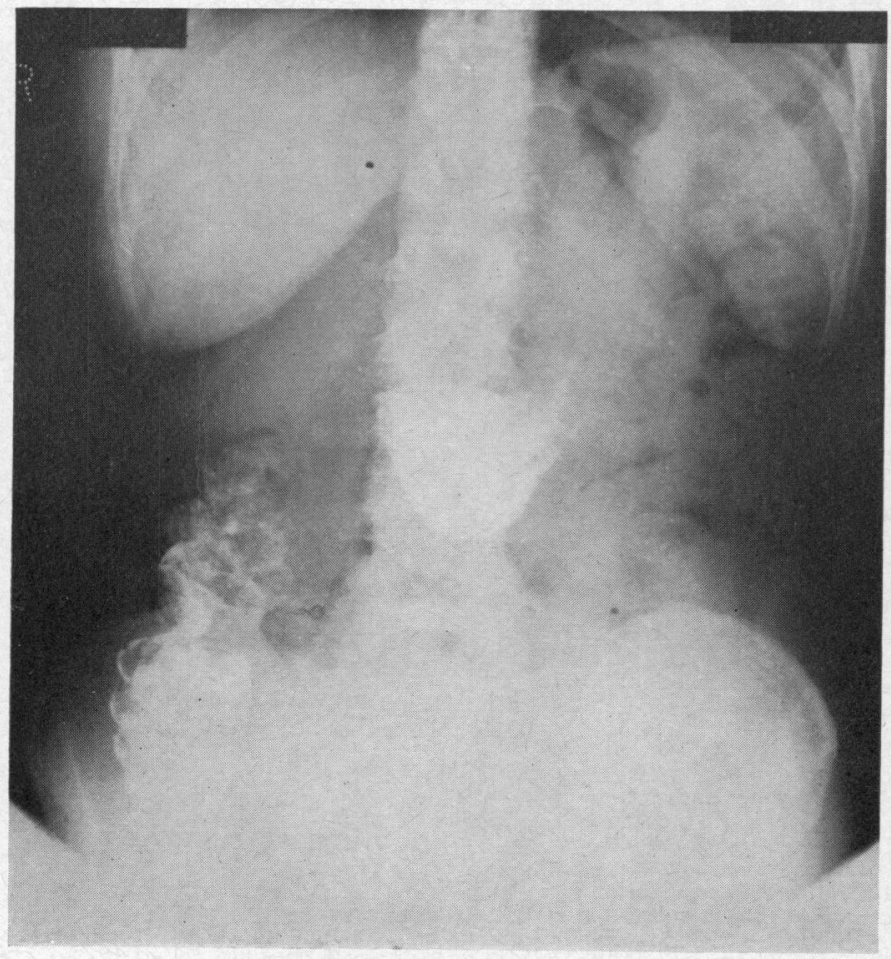

FIG. 3.-Gastric retention ++ .

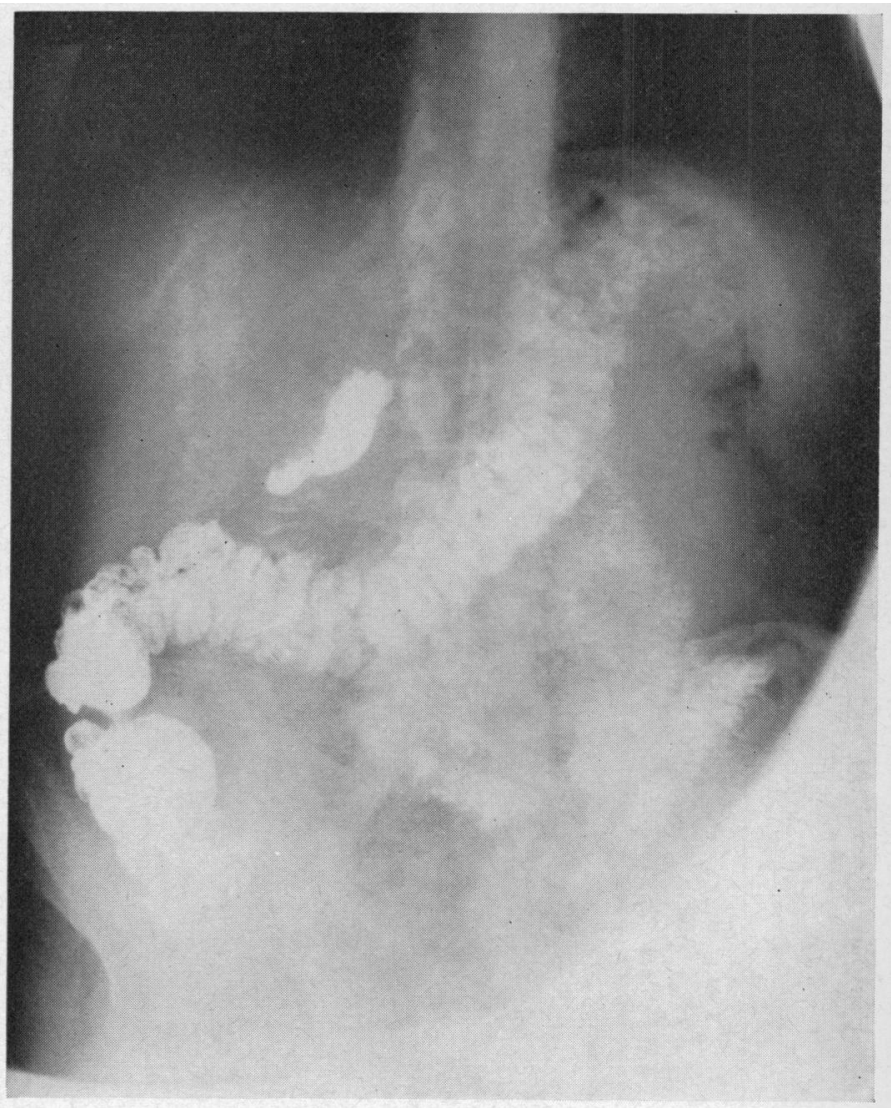

FIG. 2.-Gastric retention +.

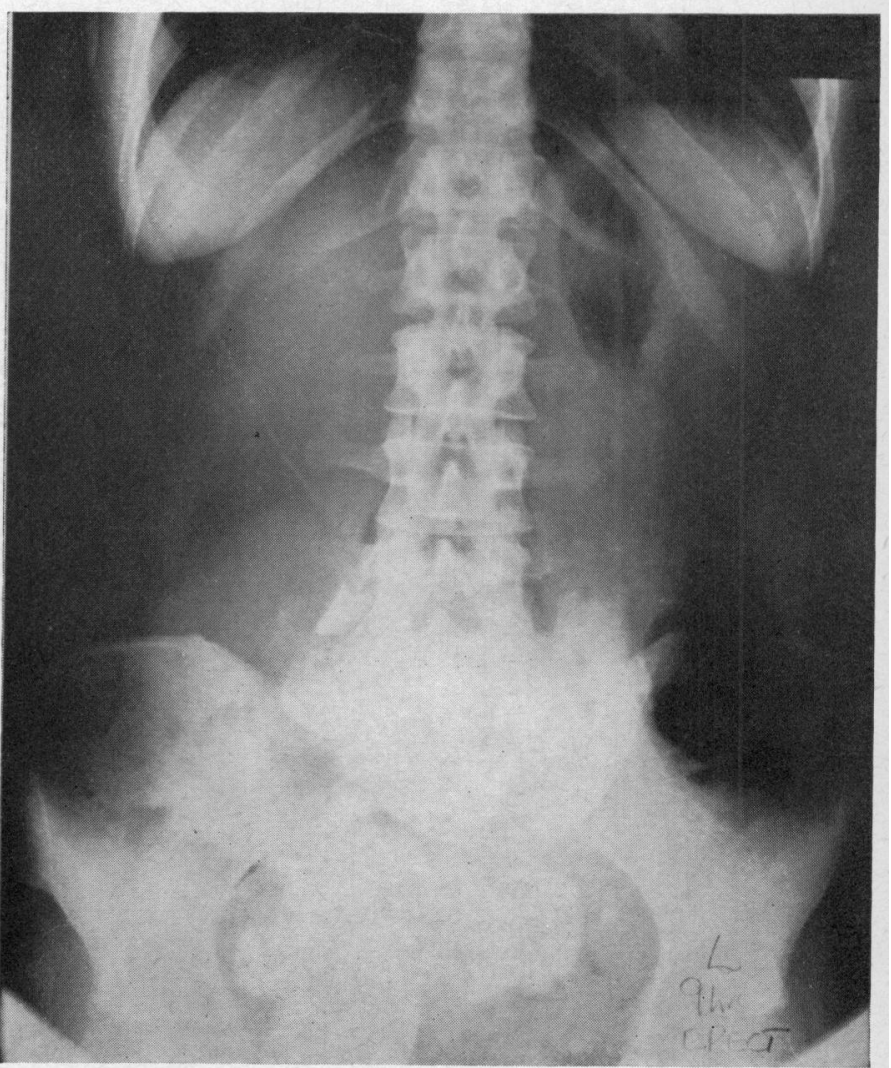

FIG. 4.-Gastric retention +++ . 
H. BURGE $E T A L .:$ SELECTIVE VAGOTOMY WITHOUT DRAINAGE

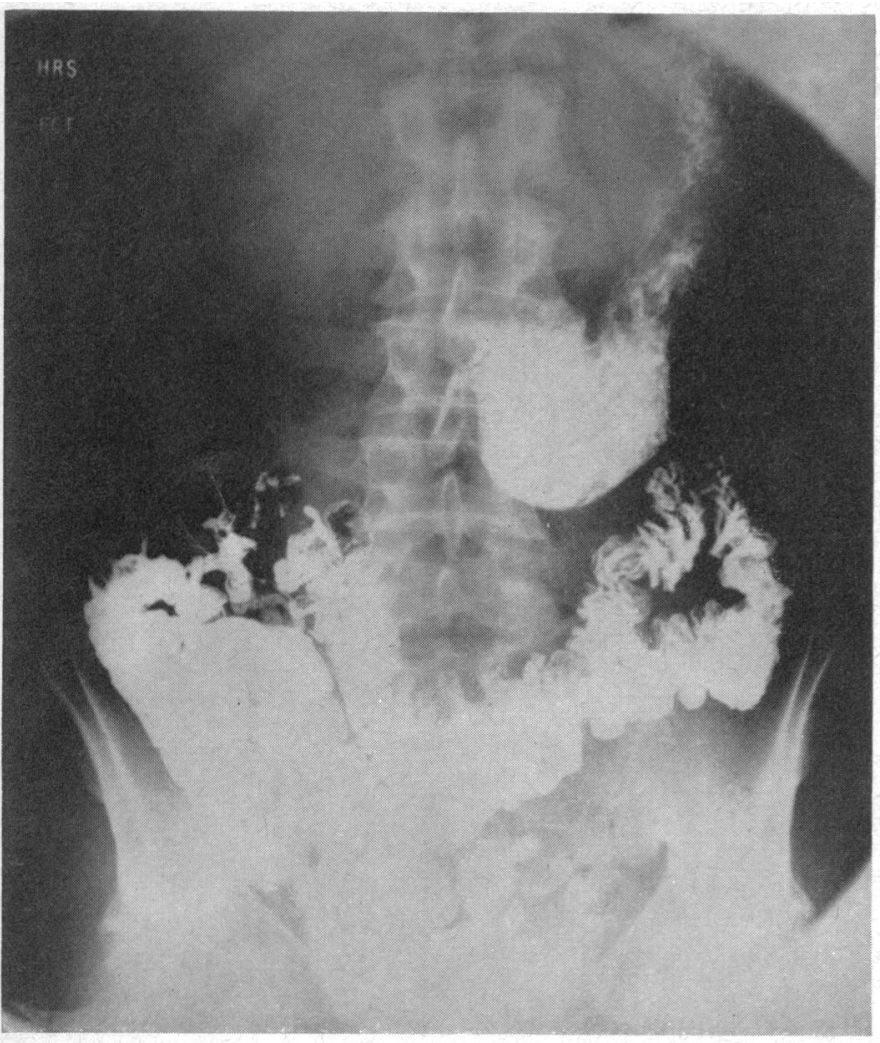

FIG. 6.-Gastric retention seven months after selective vagotomy without drainage (special meal at nine hours).

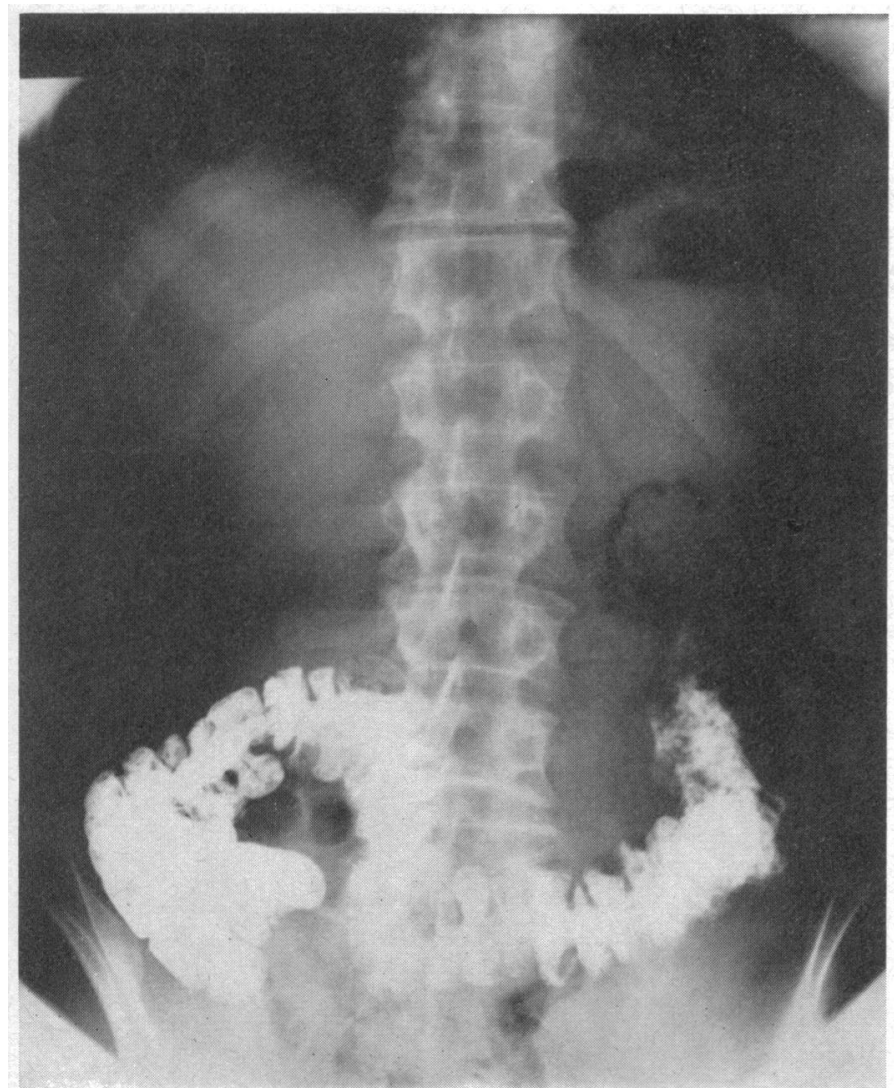

FIG. 7.-Stomach empty in same patient at 19 months after operation.

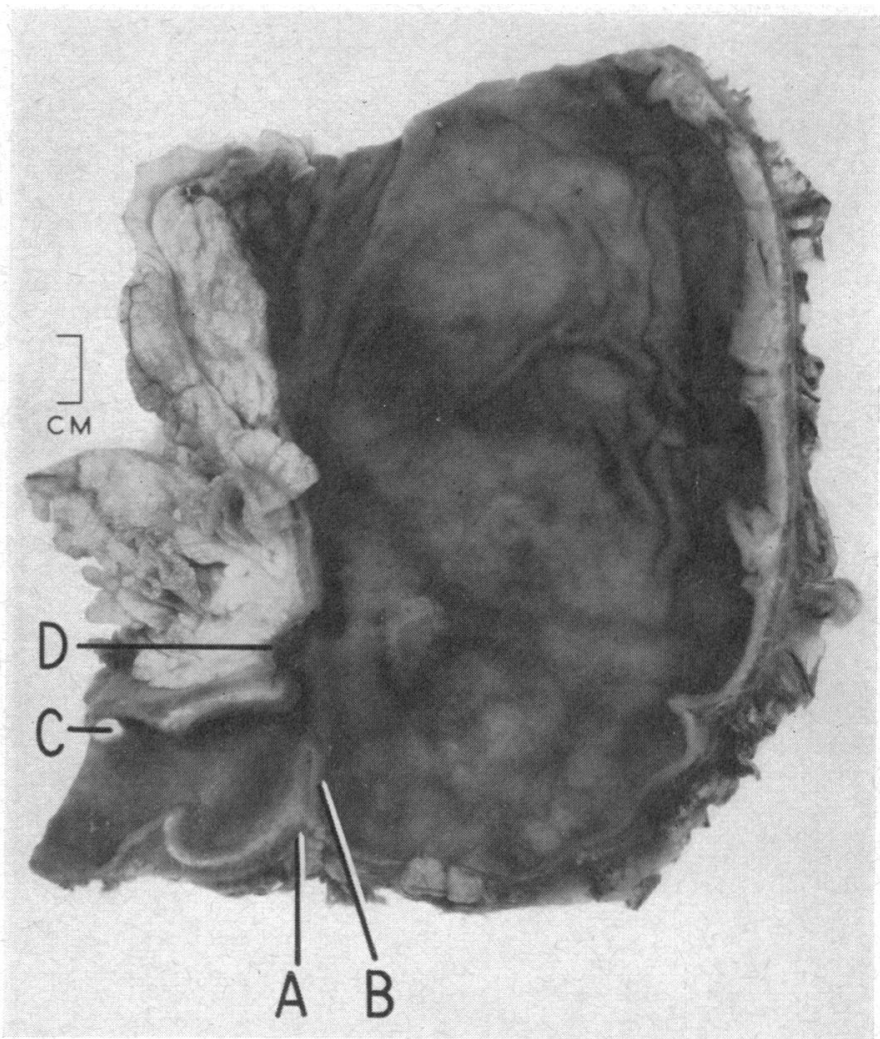

Fig. 5.- Mucosal stenosis in gastric ulcer. $A=$ Slight muscular stenosis. $B=$ Severe mucosal stenosis. $\quad C=$ Perforated duodenal ulcer. $D=$ Lesser curve gastric ulcer.

N. A. SIMMONS: POTENTIATION OF COLISTIN

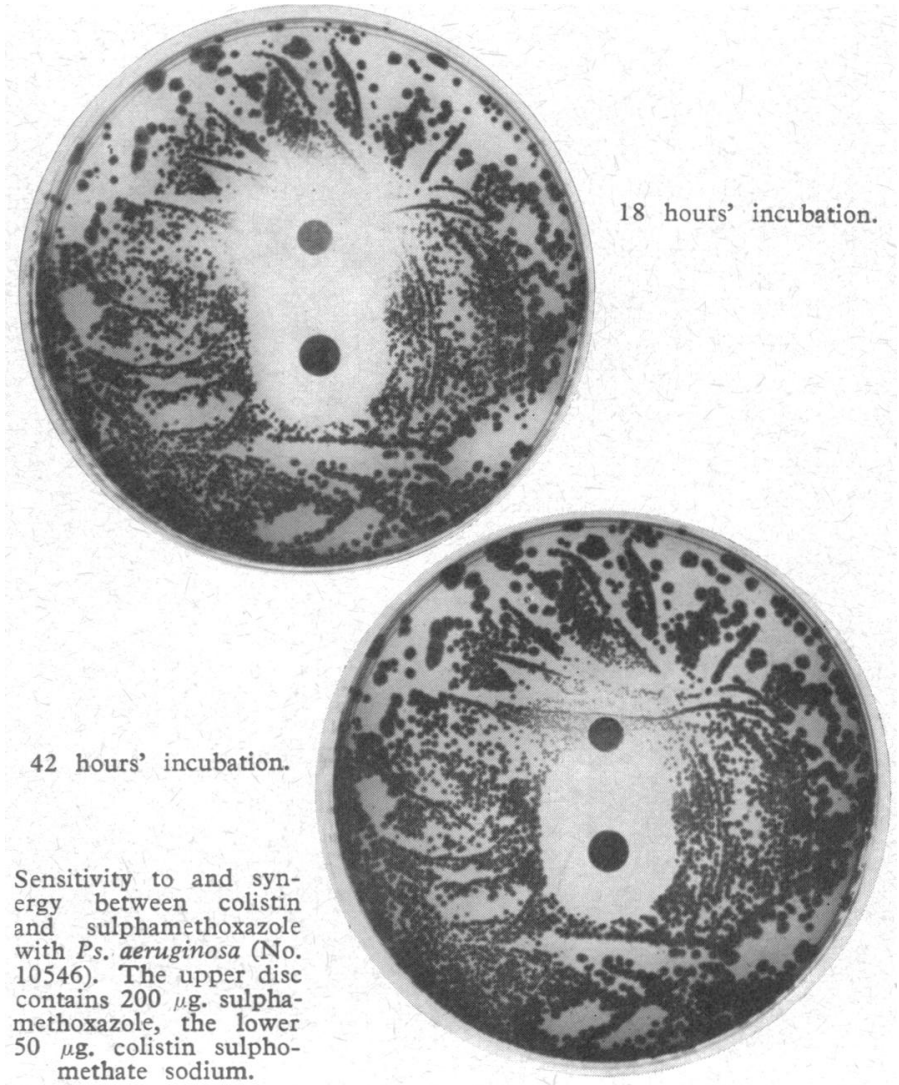


eliminates the complication of dumping, for which there is no very satisfactory treatment. Before pyloroplasty can be omitted, however, two conditions should be fulfilled. There should be very little or preferably no visible organic narrowing of the duodenum as seen at operation, and the vagotomy should be selective. It may be important to avoid damage to the lower fibres of the hepatic plexus during the anterior selective vagotomy. It is in the lowest part of this plexus that the hepatic nerves are most concentrated, forming a clearly visible structure formerly referred to erroneously as the hepatic branch of the anterior vagus (Fig. III). It is also desirable to avoid incomplete gastric nerve section; this is best done with the help of a test at the time of operation.

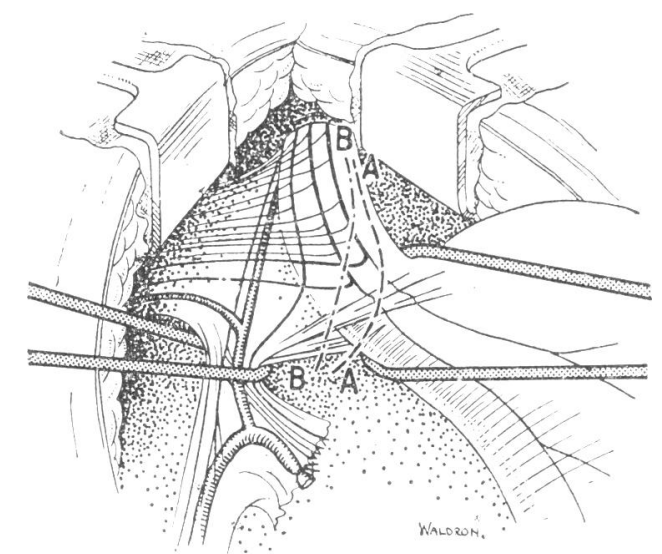

FIG. III-Line of section in anterior selective vagotomy. $\mathrm{AA}=$ Correct line of section. $\mathrm{BB}=$ Incorrect line of section.

Some of us believe that vagotomy and pyloroplasty can, and indeed should, be used in the treatment of benign gastric ulcer, no matter where the lesion may be situated in the stomach. We must now study the place of selective vagotomy without drainage in its treatment. Again it would seem logical to use the operation without drainage for gastric ulceration when there is no organic pyloric ring or duodenal stenosis. Patients with long-standing lesser curve gastric ulcer may have organic stenosis at the pylorus or in the duodenum; these will need pyloroplasty. In earlier cases gastric retention may be caused by spasm secondary to pyloric or duodenal disease in the absence of fibrotic organic stenosis. In these patients the pyloroplasty may perhaps be omitted. Our work in this field shows encouraging results.

Since series 1 and 2-without stenosis and with no pyloroplasty-were completed a further 50 patients have been treated without pyloroplasty. Great care has been taken to use pyloroplasty when there was any possibility of organic mucosal stenosis. In all, over 100 patients have been treated without any drainage procedure.

Although in this work we used the preoperative "special" barium meal to assess pyloroduodenal stenosis, more recent observations have shown that even an empty stomach at six hours should not be accepted as evidence that pyloroplasty may be omitted. An empty film at this time may be found in the presence of quite severe organic stenosis. Probably it is wise to omit pyloroplasty only when at operation the duodenum is quite free from narrowing.

If selective vagotomy without drainage should become the accepted operation for duodenal ulcer it would follow that prolonged conservative treatment which allows time for fibrous stenosis to occur must be deprecated. The trend would therefore be towards earlier though not necessarily premature operation, and there would be even more reason for choosing selective rather than truncal vagotomy.

We would like to thank the Dan Mason Research Foundation of the West London Hospital Medical Trust for its continued support.

\section{REFERENCES}

Agostoni, E., Chinnock, J. R., Daly, M. de Burgh, and Murray, J. G. (1957). Fournal of Physiology, 135, 182.

Buckler, K. G. (1967). Gut, 8, 137.

Burge, H. (1968). The Physiology of Gastric Secretion, p. 27. Oslo, Universitetsforlaget.

Franksson, C. (1948). Acta Chirurgica Scandinavica, 96, 409.

Franksson, C. (1948). Acta Chirurgice
George, J. D. (1968). Gut, 9, 237.

George, J. D. (1968). Gut, 9, 237 .
Linares, C. A., de la Rosa, C., Woodward, E. R., and Dragstedt, L. R. (1964). A., de la Rosa, C., Woodward,

Stavney, L. S., Kato, T., Griffith, C. A., Nyhus, L. M., and Harkins, H. N. (1963). Fournal of Surgical Research, 3, 390.

Van Yzeren, W. (1901). Zeitschrift für Klinische Medizin, 43, 181.

Wastell, C. (1966). British Medical fournal, 1, 1198.

\title{
Potentiation of Inhibitory Activity of Colistin on Pseudomonas aeruginosa by Sulphamethoxazole and Sulphamethizole
}

\author{
N. A. SIMMONS, * M.B., M.C.PATH. \\ with the Technical Assistance of D. J. McGillicudDy, $\dagger$ A.I.S.T. \\ [With Special Plate between Pages 692-693]
}

British Medical fournal, 1969, 3, 693-696

Cummary : Potentiation of colistin by sulphamethoxazole $\checkmark$ and sulphamethizole was demonstrated with 19 out of 20 strains of Pseudomonas aeruginosa. This enhancement was bactericidal as well as bacteriostatic. Synergy between trimethoprim and sulphamethoxazole was also demonstrated with four strains of Ps. aeruginosa, but even when the two drugs were combined high concentrations of trimethoprim were still required to produce a bactericidal effect. Combinations of sulphamethoxazole and gentamicin appeared to be synergistic when the bacteriostatic effect was measured, but the combined bactericidal effect was indifference. The bactericidal and bacteriostatic effect of combinations of carbenicillin with sulphamethoxazole was also indifference.

\section{Introduction}

In an investigation of urinary tract infection eight strains of Pseudomonas aeruginosa were isolated and were found to be moderately sensitive to sulphamethizole (Urolucosil). Subsequently most were shown to be more sensitive to sulphamethoxazole (Gantanol). Though inhibition of the growth of these bacteria by the two sulphonamides was shown, in normal circumstances they are only bacteriostatic, and pseudomonas infections are extremely difficult to eradicate. Consequently the inhibitory effect of the sulphonamides alone was considered

* Consultant Pathologist, Chase Farm Hospital, Enfield, Middlesex. t Research Technician, supported by grants from Lederle Laboratories and the North-east Metropolitan Regional Hospital Board. 